\title{
Eficiência bancária: os maiores bancos são os mais eficientes? Uma análise por envoltória de dados
}

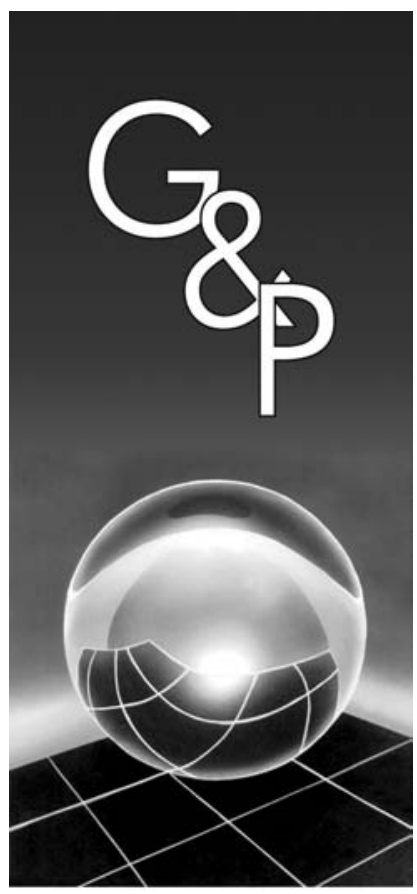

\author{
Ana Elisa Périco \\ Daisy Aparecida do Nascimento Rebelatto \\ Naja Brandão Santana
}

Resumo

A eficiência adquiriu maior relevância entre as organizações no cenário de mercados abertos, que teve início no Brasil, por volta dos anos 90. O objetivo deste artigo é analisar, por envoltória de dados (data envelopment analysis - DEA), a eficiência dos bancos comerciais instalados no país, utilizando a base de dados intitulada "Os Maiores Bancos", do ano de 2005, divulgada periodicamente pelo Banco Central do Brasil. A DEA é uma técnica de pesquisa operacional, que tem como base a programação linear e cujo objetivo é analisar comparativamente unidades independentes. A técnica foi aplicada para as 12 maiores organizações bancárias comerciais, de forma a verificar se as mesmas são consideradas eficientes, no que diz respeito à utilização dos seus recursos. Os resultados encontrados permitiram concluir que a grandeza de um banco (critério utilizado pelo Banco Central para a classificação dos bancos) não foi determinante para atribuir a eficiência a cada um deles. Convém salientar, também, que a utilização dos recursos (inputs) para o alcance do produto (output), foi o critério mais relevante na busca do bom desempenho e da eficiência bancária no estudo aqui relatado.

Palavras-chave: Análise por envoltória de dados. Eficiência. Bancos comerciais.

\section{Introdução}

Com a abertura comercial, iniciada no Brasil no início dos anos 90, a questão da eficiência no atendimento às demandas de clientes tornou-se premente. Nesse cenário que assim se instalou, a busca da eficiência abrangeu desde as indústrias produtoras de bens até as instituições prestadoras de serviços.

Nesse novo ambiente, o consenso a que se chegou deixou transparecer que as exigências do consumidor não se restringem apenas ao bem ou ao serviço em si. Satisfazer a demanda do cliente, nos dias de hoje, significa ofertar grande diversidade de produtos/serviços, maior qualidade dos mesmos e melhorar a relação custo/ benefício. Além disso, existem evidências de que a disponibilidade de um bom serviço na fase pós-venda faz melhorar a percepção e a aceitação do cliente para com a empresa produtora do bem ou prestadora do serviço.

$\mathrm{O}$ que significa dizer que "o consumidor não quer apenas o bem ou o serviço em si" quando se trata de empresas prestadoras de serviços? Quer dizer que o cliente não quer apenas o "serviço básico", ele quer algo além, algo que agregue mais valor.

O ambiente bancário é um exemplo clássico dessa situação. A função original de um banco comercial é a de intermediar a relação depósitos - operações de crédito. No entanto, já vai longe a época em que os estabelecimentos bancários executavam apenas essas operações. Atualmente, os serviços bancários são executados transformando capital humano, físico e financeiro (entradas) em montantes emprestados e serviços agregados (saídas).

A concorrência, que se tornou acirrada, fez aumentar o escopo das funções de um banco comercial. Os simples depósitos e empréstimos são as funções básicas que qualquer banco pode oferecer. Entretanto, o gerenciamento de aplicações e de investimentos, de fundos de previdência privada, de financiamentos diversos, de securitização e outras mais, são algumas das funções "complementares" de um banco comercial nos dias de hoje.

É justamente nesse cenário, em que o banco comercial passa a executar muitas funções e onde há muitos concorrentes, que surge uma questão fundamental para esse tipo de organização: o que é mais importante nesse ambiente, ser o maior banco ou ser o melhor gerenciador de recursos?

$\mathrm{Na}$ busca de respostas a esse questionamento deve-se partir da premissa de que o maior banco é aquele que possui mais recursos financeiros, ou seja, o mais rico, de 
acordo com a classificação do Banco Central do Brasil. Por outro lado, considera-se o melhor gerenciador aquele banco que, dispondo da mesma quantidade de recursos (inputs) que os seus concorrentes, tem a capacidade de produzir mais serviços (saídas).

A questão que se coloca agora, em torno do melhor gerenciador, está estreitamente relacionada ao conceito de eficiência. Dessa forma, a pergunta que se formula é: O maior banco é, também, o banco mais eficiente?

Com base nessas explanações, cabe mencionar que o objetivo do trabalho que está relatado neste artigo é analisar, por envoltória de dados, a eficiência dos bancos comerciais instalados no país, utilizando a base de dados intitulada "Os Maiores Bancos", do ano de 2005, divulgada periodicamente pelo Banco Central do Brasil.

Como parte integrante dos procedimentos metodológicos, para alcançar o objetivo proposto, inicialmente foi realizado um levantamento de informações que teve como finalidade principal resumir as características do Sistema Financeiro Nacional, ressaltar as principais funções dos bancos comerciais, assim como identificar alguns trabalhos já produzidos sobre a eficiência bancária.

Em um segundo momento, foi apresentado o modelo de análise por envoltória de dados (DEA), uma das principais técnicas para mensurar a eficiência de organizações. As abordagens teórica e matemática deste modelo estão apresentadas neste trabalho.

A parte subseqüente teve como objetivo a identificação dos bancos que foram analisados, a escolha das variáveis (de entrada e de saída) para este caso específico, assim como a aplicação do modelo proposto às unidades em análise e a apresentação dos resultados obtidos.

A conclusão do trabalho apresenta o índice de eficiência para cada banco analisado, explorando, principalmente, as divergências entre o indicador do Banco Central e os escores de eficiência obtidos por meio do modelo proposto.

\section{Sistema financeiro nacional}

De acordo com o Banco Central do Brasil (2006), o sistema financeiro nacional (SFN) possui duas funções, uma normativa e outra operacional. A função normativa visa regular e fiscalizar o mercado financeiro e é representada, principalmente, pelos seguintes órgãos: Banco Central do Brasil, Comissão de Valores Monetários e Conselho Monetário Nacional. A função operacional é realizada por meio de várias instituições financeiras, assim denominadas:

a) monetárias ou captadoras de depósitos à vista;

b) de crédito;

c) de capitais;

d) de câmbio; e

e) de seguro e previdência.
Entre essas instituições financeiras é possível identificar os bancos comerciais, os bancos de investimento e desenvolvimento, a Bolsa de Valores, as sociedades seguradoras, entre outras.

Cabe notar que a captação, via depósito à vista, livremente movimentável pelo público, é uma atividade típica dos bancos comerciais. É com base nesta atividade que eles se inserem na categoria de instituições financeiras monetárias. Um dos critérios utilizados para a escolha do banco comercial como objeto de análise deste trabalho foi o fato de que ele representa a instituição mais dinâmica do sistema financeiro, sendo responsável por uma maior movimentação de recursos.

São encontradas, tanto na literatura nacional como na internacional, sobre Economia Monetária, as características dos bancos comerciais, e as opiniões dos estudiosos têm sido unânimes quanto à sua função básica, ou seja, a de atender à demanda por crédito de tomadores de recursos e também às expectativas de aplicações de agentes poupadores (GUDIN, 1974; CHICK, 1986; MAYER, 1993; LOPES; ROSSETTI, 1998; HOWELLS; BAIN, 2001; MISHKIN, 2000; GITMAN, 2004; ASSAF NETO, 2005).

Uma característica importante dos bancos comerciais identifica-se com a sua capacidade de interferir nos meios de pagamento da economia, pela criação da moeda escritural. Com base no volume de depósitos à vista, captados no mercado, verifica-se que uma parte desses recursos depositados nos bancos é retida sob a forma de reservas financeiras, sendo a parcela disponível devolvida ao mercado sob a forma de empréstimos. Esses recursos, por sua vez, voltam novamente ao caixa do sistema bancário, gerando novos empréstimos, e assim por diante. Nesse processo contínuo, os bancos passam a criar moeda dos depósitos à vista captados, alterando sua oferta na economia.

Para Assaf Neto (2005), os bancos constituem as maiores instituições do sistema financeiro e atualmente vêm expandindo suas atuações por meio da prestação de diversos serviços aos seus correntistas, como cobranças, seguros, corretagens, transferências de fundos, ordens de pagamento, serviço de câmbio, etc.

É oportuno ressaltar que a função básica de conceder empréstimos financiados por depósitos já não é realizada somente pelos bancos comerciais, na atualidade. No entanto, o declínio da participação dos bancos comerciais no mercado, no total de empréstimos e no total de ativos de intermediários financeiros, não é um indicador que o setor bancário esteja em decadência, pelo contrário, este é um setor que tem apresentado crescente rentabilidade.

A Figura 1 apresenta a rentabilidade bancária em relação ao crescimento do PIB brasileiro entre 2001 e 2005 (BANCO CENTRAL, 2006). 


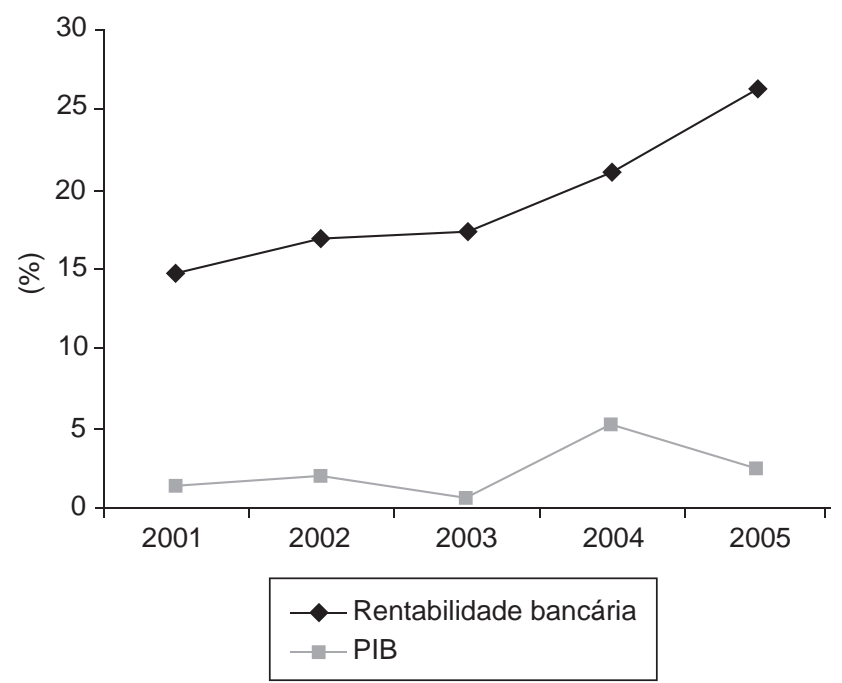

Figura 1. Gráfico da rentabilidade bancária $x$ PIB. (BACEN, 2006).

O fato do lucro dos bancos ter crescido mais do que o PIB nacional, conforme indica o gráfico, reflete, entre outras coisas, o crescimento do próprio crédito - que também foi maior do que o do PIB. Enquanto o PIB cresceu 2,3\%, em 2005, o lucro dos bancos cresceu $26,3 \%$. Isso quer dizer que, embora os depósitos e os empréstimos não sejam mais as únicas atividades dos bancos comerciais, a concessão de crédito, um dos principais fatores responsáveis pelo lucro de um banco, continuou a crescer.

A esse respeito, Mishkin (2000) ressalta, com base nos estudos que realizou, quatro grandes inovações financeiras, que vieram a complementar a função dos bancos: os fundos mútuos do mercado monetário, as obrigações emitidas por empresas (debêntures), o mercado de commercial papers e a securitização.

\subsection{Eficiência bancária}

O estudo sobre a eficiência de qualquer organização passa, necessariamente, pela questão da fronteira eficiente. Essa fronteira representa um máximo de produtividade para uma determinada quantia de recursos estabelecida, significando que, quanto menor a quantia, melhor a produtividade. Em suma, estarão mais próximas da fronteira de eficiência aquelas organizações que alcançarem maior produtividade, consumindo menos recursos.

A fronteira eficiente pode ser construída de forma paramétrica ou não paramétrica. A abordagem paramétrica impõe uma forma funcional particular, ou seja, utiliza uma função que determina os recursos necessários para alcançar um produto. Os métodos não paramétricos não especificam forma funcional, já que constroem a fronteira a partir dos dados disponíveis.
Alguns estudiosos, como Casu e Molyneux (2001), identificam as três principais abordagens que utilizam os métodos paramétricos: a stochastic frontier approach (SFA), a distribution free approach (DFA) e a thick frontier approach (TFA). As principais abordagens não paramétricas são: a data envelopment analysis - DEA (análise por envoltória de dados) e a free disposal hull (FDH).

A literatura consultada, seja nacional ou internacional, disponibiliza algumas pesquisas sobre eficiência bancária. Os trabalhos aqui apresentados utilizaram a abordagem não paramétrica, devido, principalmente, à flexibilidade em torno das variáveis que puderam ser utilizadas.

É importante ressaltar que uma parte considerável das variáveis utilizadas neste trabalho, para avaliar a eficiência, está relacionada, direta e indiretamente, à função básica do banco, ou seja, às operações de depósitos e às operações de crédito. E houve, evidentemente, aquelas variáveis relacionadas aos novos serviços prestados pelos bancos, que também influenciaram na eficiência de cada um deles.

Vedula e Tripé (2004) analisaram seis bancos neozelandeses, no período de 2000 a 2002, considerando como variáveis de entrada (input): gastos com juros, gastos operacionais, gastos com pessoal, depósitos, número de filiais, ativos fixos e fundos de empréstimos. Como variáveis de saída (outputs) foram utilizados os ganhos com juros, outros ganhos, os depósitos e os ganhos operacionais totais.

Com o mesmo objetivo de avaliar a eficiência bancária, Sathye (2002) coletou dados de 94 bancos. Para essa pesquisa, o autor construiu a sua avaliação por meio de dois modelos. Esses 94 bancos foram divididos em duas categorias: a) públicos; e b) privados. O primeiro modelo utilizava gastos com juros e gastos operacionais como entradas, e receita com juros e outras receitas como saídas. O segundo modelo utilizava depósitos e número de empregados como entradas, e apenas as receitas oriundas de serviços prestados pelo banco como saída.

Ceretta e Niederauer (2001), compararam a performance de 144 bancos brasileiros, durante o segundo semestre de 1999, combinando sete inputs (ativo circulante mais realizável a longo prazo, ativo permanente, ativo total, exigibilidade, patrimônio líquido, receita total e resultado do semestre) e três outputs (rentabilidade, liquidez geral e alavancagem). Eles constataram que os bancos de grande porte possuem maior grau de eficiência do que os de médio e pequeno porte, refletindo o que estava ocorrendo no setor no ano da pesquisa: falência de pequenas e médias instituições bancárias e a compra ou fusão entre bancos nacionais e estrangeiros.

A técnica DEA foi empregada por Camargo et al. (2004) para comparar 19 dos bancos comerciais de grande porte que atuavam no Brasil em 2003. Eles utilizaram três variáveis como entradas (ativo total, despesas de pessoal e outras despesas administrativas) e quatro variáveis 
como saídas (operações de crédito, operações de crédito de longo prazo, aplicações em tesouraria e rentabilidade da atividade bancária). Os resultados mostraram que os bancos com menores ativos totais são mais eficientes e que a única fonte de ineficiência para eles está relacionada à ordem de escala de produção.

De todos esses estudos descritos anteriormente, observa-se que não existe um padrão na escolha das variáveis de entrada (inputs) e de saída (outputs). A utilização de variáveis diferentes pode levar a resultados de eficiência distintos. Recomenda-se, então, que a seleção das variáveis seja feita de forma cautelosa, para que os resultados obtidos tenham sentido e representem a realidade da empresa. Na próxima seção será abordado um procedimento, que é considerado adequado pela literatura, para a seleção de variáveis de entrada e de saída.

\section{Análise por envoltória de dados}

A análise por envoltória de dados é uma técnica gerencial utilizada para a avaliação e a comparação de unidades organizacionais. Ao englobar um grande número de informações, transformando-as em um único índice de eficiência global, essa técnica auxilia a tomada de decisões (CERETTA; COSTA JR, 2001).

A DEA é uma técnica de pesquisa operacional, que tem como base a programação linear, cujo objetivo é analisar comparativamente unidades independentes no que se refere ao seu desempenho relativo (MACEDO; SANTOS; SILVA, 2004).

Essa técnica é classificada como não paramétrica, pois não utiliza uma função de produção pré-definida, idêntica para todas as organizações na análise do relacionamento input-output. Logo, para a sua utilização não é necessária a elaboração de uma fórmula ponderada fixa para a medição da eficiência de unidades analisadas, pois os pesos de cada uma das variáveis são determinados pela própria técnica.

Para uma melhor descrição dessa técnica, Estellita Lins e Meza (2000) destacam as suas principais características:

a) não requer, a priori, uma função de produção explícita;

b) examina a possibilidade de diferentes, mas igualmente eficientes, combinações de inputs e outputs;

c) localiza a fronteira eficiente dentro de um grupo analisado e as unidades incluídas; e

d) determina para cada unidade eficiente subgrupos de unidades eficientes, os quais formam seu conjunto de referência.

\subsection{Modelos DEA}

A DEA pode ser considerada como um corpo de conceitos e metodologias que está incorporada a uma coleção de modelos, com possibilidades interpretativas diversas (CHARNES et al., 1997). Os modelos mais largamente utilizados são o CCR e o BCC.

\subsubsection{Modelo CCR}

Desenvolvido por Charnes et al. (1978), esse modelo permite uma avaliação objetiva da eficiência global e identifica as fontes e as estimativas de montantes das ineficiências identificadas (CASA NOVA, 2002).

Há duas formulações matemáticas nas versões deste modelo, o modelo CCR com orientação para o input e o modelo CCR com orientação para o output (Quadro 1).

O objetivo central do modelo CCR com orientação para o input é buscar a eficiência a partir de alterações (reduções) nos níveis de input (insumos), mantendo constante o nível de produto (output), considerando o retorno constante de escala.

A primeira restrição pode ser definida como o resultado da empresa, pois nada mais é do que a subtração dos produtos (somatório das quantidades produzidas multiplicadas pelos pesos dos produtos) dos insumos (somatório dos insumos consumidos multiplicados pelos respectivos pesos). Ele está limitado a 0. Dessa forma, as empresas eficientes obterão resultado 0 .

A segunda restrição é o somatório da multiplicação das quantidades consumidas pelos pesos específicos para a empresa $\mathrm{K}$, devendo ser igual a 1 . Se a empresa $\mathrm{K}$ for eficiente, $h_{k}$ será igual a 1 . Se não for, obterá um indicador sempre inferior a 1 .

O objetivo do modelo CCR com orientação ao output é a maximização do nível de produção, utilizando, no máximo, o consumo de inputs observados. As restrições são as mesmas do modelo CCR com orientação para o input.

Quadro 1. Modelos CCR. (PÉRICO et al., 2008).

\begin{tabular}{|c|c|}
\hline $\begin{array}{c}\text { Modelo CCR - } \\
\text { Orientação input }\end{array}$ & $\begin{array}{c}\text { Modelo CCR - } \\
\text { Orientação output }\end{array}$ \\
\hline $\begin{array}{l}\text { Maximizar } \mathrm{h}_{\mathrm{k}}=\sum_{r=1}^{s} u_{r} y_{r k} \\
\text { Sujeito a: } \\
\sum_{r=1}^{m} u_{r} y_{r j}-\sum_{i=1}^{n} v_{i} x_{i j} \leq 0\end{array}$ & $\begin{array}{l}\text { Minimizar } \mathrm{h}_{\mathrm{k}}=\sum_{i=1}^{n} v_{i} x_{i k} \\
\text { Sujeito a: } \\
\sum_{r=1}^{m} u_{r} y_{r j}-\sum_{i=1}^{n} v_{i} x_{i j} \leq 0\end{array}$ \\
\hline$\sum_{i=1}^{n} v_{i} x_{i k}=1$ & $\sum_{r=1}^{m} u_{r} y_{r k}=1$ \\
\hline $\mathrm{u}_{\mathrm{r}}, \mathrm{v}_{\mathrm{i}} \geq 0$ & $u_{\mathrm{r}}, \mathrm{v}_{\mathrm{i}} \geq 0$ \\
\hline $\begin{array}{l}\text { Considerando: } \\
\mathrm{y}=\text { outputs; } \mathrm{x}=\text { inputs; } \\
\mathrm{u}, \mathrm{v}=\text { pesos; } \\
\mathrm{r}=1, \ldots, \mathrm{m} ; \mathrm{i}=1, \ldots, \mathrm{n} ; \mathrm{e} \\
\mathrm{j}=1, \ldots, \mathrm{N}\end{array}$ & $\begin{array}{l}\text { Considerando: } \\
\mathrm{y}=\text { outputs; } \mathrm{x}=\text { inputs; } \\
\mathrm{u}, \mathrm{v}=\text { pesos; } \\
\mathrm{r}=1, \ldots, \mathrm{m} ; \mathrm{i}=1, \ldots, \mathrm{n} ; \mathrm{e} \\
\mathrm{j}=1, \ldots, \mathrm{N}\end{array}$ \\
\hline
\end{tabular}


$\mathrm{O}$ indicador de eficiência do modelo CCR indica uma medida de produtividade global, denominada de indicador de eficiência produtiva.

\subsubsection{Modelo BCC}

Criado por Banker et al. (1984), esse modelo distingue entre ineficiência técnica e de escala, estimando a eficiência técnica pura a uma dada escala de operações, e identificando se estão presentes ganhos de escala crescentes, decrescentes ou constantes, para futura exploração.

De acordo com Belloni (2000), o indicador da eficiência técnica resultante da aplicação do modelo BCC permite identificar a ineficiência técnica, isolando da ineficiência produtiva o componente associado à ineficiência de escala. Livre das dificuldades advindas de considerar a escala de produção, o modelo possibilita a utilização de unidades de referência de portes distintos.

O Quadro 2, apresentado a seguir, apresenta as formulações matemáticas dos dois modelos BCC.

A variável $u_{k}$ é introduzida representando os retornos variáveis de escala. Segundo Casa Nova (2002), essa variável não deve atender à restrição de positividade, podendo assumir valores negativos.

\subsection{Etapas de aplicação dos modelos DEA}

Para a aplicação dos modelos DEA é necessário uma sequiência de etapas, sendo elas:

a) Seleção das unidades a entrarem na análise;

b) Seleção das variáveis (input e output) apropriadas para estabelecer a eficiência relativa das unidades selecionadas; e

c) Identificação da orientação do modelo e retornos de escala.

Quadro 2. Modelos BCC. (PÉRICO et al., 2008).

\begin{tabular}{ll}
\hline \multicolumn{1}{c}{$\begin{array}{c}\text { Modelo BCC - } \\
\text { Orientação input }\end{array}$} & \multicolumn{1}{c}{$\begin{array}{c}\text { Modelo BCC - } \\
\text { Orientação output }\end{array}$} \\
\hline $\begin{array}{l}\text { Maximizar } \sum_{r=1}^{m} u_{r} y_{r k}-u_{k} \\
\text { Sujeito a: }\end{array}$ & $\begin{array}{l}\text { Minimizar } \sum_{i=1}^{n} v_{i} x_{k i}+v_{k} \\
\text { Sujeito a: }\end{array}$ \\
$\sum_{r=1}^{n} v_{i} x_{i k}=1$ & $\sum_{r=1}^{m} u_{r} y_{r k}=1$ \\
$\sum_{r=1}^{m}$ uryrj $-\sum_{i=1}^{n} v_{i} x_{i j}-u_{k} \leq 0$ & $\sum_{r=1}^{m} u_{r} y_{j r}-\sum_{i=1}^{n} v_{i} x_{j r}-v_{k} \leq 0$ \\
$\mathrm{u}_{\mathrm{r}}, \mathrm{v}_{\mathrm{i}} \geq 0$ & $\mathrm{u}_{\mathrm{r}}, \mathrm{v}_{\mathrm{i}} \geq 0$ \\
Considerando: & Considerando: \\
$\mathrm{y}=$ outputs; $\mathrm{x}=$ inputs; & $\mathrm{y}=$ outputs; $\mathrm{x}=$ inputs; \\
$\mathrm{u}, \mathrm{v}=$ pesos; & $\mathrm{u}, \mathrm{v}=$ pesos; \\
$\mathrm{r}=1, \ldots, \mathrm{m} ; \mathrm{i}=1, \ldots, \mathrm{n} ; \mathrm{e}$ & $\mathrm{r}=1, \ldots, \mathrm{m} ; \mathrm{i}=1, \ldots, \mathrm{n} ; \mathrm{e}$ \\
$\mathrm{j}=1, \ldots, \mathrm{N}$ & $\mathrm{j}=1, \ldots, \mathrm{N}$ \\
\hline
\end{tabular}

Na seleção das unidades, a DEA determina que as unidades a serem analisadas sejam chamadas de decision making units (DMUs). Para Lins e Meza (2000), a primeira observação a ser feita diz respeito à homogeneidade das DMUs. Por DMUs homogêneas entende-se que são aquelas que realizam as mesmas tarefas com os mesmos objetivos, que estejam trabalhando nas mesmas condições de mercado, e tais que as variáveis utilizadas sejam iguais, com exceção da sua magnitude. As unidades a serem avaliadas necessitam ser suficientemente semelhantes, de forma que a comparação faça sentido, mas também suficientemente diferentes, de forma que possamos discriminá-las.

Já para a seleção das variáveis, a técnica DEA considera, inicialmente, uma grande lista de possibilidades. O acréscimo de muitas variáveis reduz a capacidade da DEA de discriminar as DMUs eficientes das ineficientes. Dessa forma, o modelo deve ser mantido o mais compacto possível para maximizar o poder discriminatório da DEA.

Em grande parte da literatura existente sobre o assunto, os autores limitam-se a afirmar que as variáveis selecionadas são as que melhor descrevem a performance das DMUs sob análise, sem mencionar maiores explicações a respeito da melhor forma de selecioná-las. Conforme Thanassoulis (1996), a possibilidade de alteração no conjunto selecionado de input ou output é uma realidade que terá importantes repercussões no resultado do processo de avaliação.

Norman e Stoker (1991) propuseram o primeiro procedimento sistematizado para seleção de variáveis, inspirado no método stepwise (passo a passo). O método parte de um par de input-outputs inicial, calcula o score de eficiência das DMUs com base neste par, e os coeficientes de correlação de todas as demais variáveis com estes scores. Para selecionar a próxima variável a entrar no modelo, a lista de variáveis é percorrida em ordem decrescente do módulo do coeficiente de correlação.

O método stepwise reconhece que existe uma informação prévia acerca da variável candidata, se ela é um input ou output, e estabelece critérios distintos para a seleção. O objetivo é incorporar a variável que permitirá um melhor ajuste das DMUs à fronteira da eficiência.

Nos modelos DEA, a inclusão de um fator pode não acarretar redução na eficiência de qualquer DMU. Fatores que não alteram significativamente os escores de eficiência também serão identificados como fatores que não contribuem para que as DMUs se aproximem, em média, da fronteira de eficiência. Tais fatores não serão incorporados ao modelo.

Segundo Lins e Meza (2000), variáveis adicionais são acrescentadas e é escolhido, para a continuidade do algoritmo, aquele cenário com maior eficiência média. A 
seleção termina quando a variável adicionada não produz incremento significativo à eficiência média.

$\mathrm{Na}$ terceira etapa, que consiste na identificação da orientação do modelo e retornos de escala, são definidos os modelos que melhor representam a tecnologia de produção, havendo a necessidade de fazer algumas ressalvas, principalmente no que diz respeito à orientação e ao tipo de retorno de escala.

O modelo de eficiência pode responder a qualquer uma das duas perguntas:

a) As unidades produzem determinado nível de output, ora, quanto é possível reduzir os inputs mantendo o nível atual de output? Isto significa minimizar os inputs; $\mathrm{e}$

b) As unidades utilizam determinado nível de input, qual é o maior nível de output que pode ser alcançado com esse nível de input? Isto significa maximizar os outputs.

A orientação para o input indica que o objetivo será de reduzir os insumos sem alterar o nível atual dos outputs; a orientação para o output tem como objetivo aumentar os outputs, porém, mantendo fixo o nível de input.

A relação entre inputs e outputs é denominada retorno de escala. Brunetta (2004) ressalta duas possibilidades de retornos nos modelos DEA: retorno constante de escala (CRS) e retornos variáveis de escala (VRS). Para esse autor, uma tecnologia apresenta retorno constante de escala quando os inputs aumentam ou diminuem numa mesma proporção dos outputs, isto é, quando os inputs aumentam ou diminuem num fator $\lambda$. Sendo $\lambda$ um escalar positivo, a produção irá aumentar ou diminuir por este mesmo fator $\lambda$.

Uma tecnologia apresenta retorno variável de escala quando os inputs são multiplicados por um fator $\lambda$, os outputs podem seguir qualquer comportamento em relação a este fator $\lambda$ (BRUNETTA, 2004).

\section{Método da pesquisa empírica}

Nesta seção são apresentados os passos de procedimento adotados na parte empírica deste trabalho. Devido ao fato de, em determinados momentos, não ser possível identificar claramente as etapas de aplicação dos modelos DEA, uma vez que elas podem acontecer de forma simultânea, cabe mencionar que o modelo DEA utilizado neste trabalho foi o BCC, com orientação para o output e com retornos variáveis de escala.

\subsection{A base de dados}

Os dados utilizados na pesquisa empírica deste trabalho foram os registros financeiros anuais das instituições bancárias, referentes ao ano de 2005, obtidos no site do Banco Central do Brasil (www.bcb.gov.br), no relatório "50 Maiores Bancos", acessado em julho de 2006.
A seleção do período de análise se deveu à disponibilidade de dados pelo Banco Central, tendo sido considerado o período mais recente com dados totalmente disponibilizados.

\subsection{A amostra}

Em concordância com o objetivo maior deste trabalho, que é realizar uma análise por envoltória de dados, de forma a verificar se os maiores bancos são, de fato, os mais eficientes, a amostra desta pesquisa foi delimitada em 12 bancos comerciais, respeitando o ranking classificatório elaborado pelo Banco Central.

A exclusão dos demais bancos da análise é justificada por dois motivos. Primeiro, pelo fato de não ser objetivo deste artigo explorar, exaustivamente, a questão de quais são os bancos eficientes e quais não são, dentre os 50 bancos selecionados pelo Banco Central, mas sim demonstrar, de forma sucinta, mas legítima, que nem sempre os maiores bancos são considerados os mais eficientes. Para tanto, uma amostra pequena é suficiente.

$\mathrm{O}$ segundo motivo está relacionado à disponibilidade do software Frontier na versão limitada (demo), utilizado para realizar análises por envoltória de dados. O software limitado comporta uma quantidade restrita de unidades para análise.

A Tabela 1 apresenta a classificação dos 12 maiores bancos comerciais, de acordo com o critério do Banco Central do Brasil.

\subsection{Seleção de variáveis e aplicação do modelo}

A partir do banco de dados disponível, as variáveis foram pré-selecionadas, considerando como justificativa principal nesta pré-seleção, a disponibilidade de informações.

Cabe ressaltar, que o banco de dados do Banco Central utilizou como variáveis aquelas que possuíam alguma relação com o parâmetro selecionado, a grandeza de

Tabela 1. Classificação dos maiores bancos comerciais brasileiros. (BANCO CENTRAL, 2006).

\begin{tabular}{lc}
\hline \multicolumn{1}{c}{ Banco } & Classificação \\
\hline Banco do Brasil & $1^{\circ}$ \\
Bradesco & $2^{\circ}$ \\
Caixa Econômica Federal & $3^{\circ}$ \\
Itaú & $4^{\circ}$ \\
Unibanco & $5^{\circ}$ \\
Santander Banespa & $6^{\circ}$ \\
ABN AMRO Real & $7^{\circ}$ \\
HSBC Bank Brasil & $8^{\circ}$ \\
Votorantim & $9^{\circ}$ \\
Safra & $10^{\circ}$ \\
Nossa Caixa & $11^{\circ}$ \\
Citibank & $12^{\circ}$ \\
\hline
\end{tabular}


um estabelecimento bancário. É importante pontuar que a escolha das variáveis, realizada pelo Banco Central, não foi realizada de maneira descuidada. Portanto, neste estudo, serão consideradas na primeira escolha de variáveis, aquelas selecionadas pelo Banco Central, que são apresentadas na Tabela 2.

Uma vez que a pré-seleção das variáveis foi realizada, cabe agora selecionar as variáveis que de fato vão compor o modelo. A literatura sobre análise por envoltória de dados sugere que seja realizado o procedimento stepwise. Este procedimento reconhece que existe uma informação prévia sobre se a variável candidata é um input ou output, conforme estabelecido pela Tabela 3 .

A Tabela 4, vista a seguir, apresenta as correlações mais significativas entre as variáveis de input e output.

A escolha para compor o par inicial de input $\mathrm{x}$ output recaiu sobre patrimônio líquido e resultado líquido. O modelo inicial foi construído com base nessas duas variáveis. A Tabela 5 apresenta os resultados da análise para o modelo inicial e a primeira etapa de inclusão de variáveis.

O resultado da aplicação do modelo inicial acusou que, utilizando a amostra de 12 bancos analisados, a eficiência média foi de $24,41 \%$, nenhum banco foi considerado eficiente e todos tiveram seus respectivos índices de eficiência abaixo de 50\%. Em outras palavras, embora o grau de associação entre as variáveis de patrimônio líquido e resultado líquido seja elevado, a primeira variável, isoladamente, não é capaz de explicar variações relevantes na

Tabela 2. Variáveis relevantes (critério do Banco Central). (BANCO CENTRAL, 2006).

\begin{tabular}{cc}
\hline Variáveis \\
\hline Ativo total \\
Operações de crédito \\
Depósitos \\
Patrimônio líquido \\
Receita financeira \\
Resultado financeiro \\
Resultado operacional \\
Resultado líquido \\
\hline
\end{tabular}

Tabela 3. Classificação das variáveis. (PÉRICO et al., 2008).

\begin{tabular}{lc}
\hline \multicolumn{1}{c}{ Variáveis } & Classificação \\
\hline Ativo total & Input \\
Operações de crédito & Input \\
Depósitos & Input \\
Patrimônio líquido & Input \\
Receita financeira & Output \\
Resultado financeiro & Output \\
Resultado operacional & Output \\
Resultado líquido & Output \\
\hline
\end{tabular}

segunda, por esse motivo, o índice de eficiência média, utilizando este modelo, é considerado baixo.

A Tabela 6 resume as informações para a primeira etapa, em que foi escolhida a terceira variável a compor o modelo.

Para selecionar a próxima variável a entrar no modelo, calcula-se a correlação de cada variável que restou, com o escore de eficiência obtido no modelo, utilizando as duas variáveis selecionadas inicialmente. A variável deve ser incluída, considerando a maior correlação positiva para input ou a maior correlação negativa para output. Portanto, neste caso, a variável selecionada é a de ativo total.

O resultado da aplicação deste modelo, com três variáveis (ativo total, patrimônio líquido e resultado líquido), acusou que, utilizando a amostra de 12 bancos analisados, a eficiência média foi de 79,37\%; quatro bancos foram considerados eficientes e nenhum banco obteve índice de eficiência abaixo de $50 \%$.

Repetiu-se esse procedimento até o ponto de parada. Neste ponto o acréscimo na eficiência média, com a inclusão de outras variáveis, é mínimo. A análise de correlação não indicou qualquer variável como relevante. Dessa forma, o modelo final considerou as variáveis:

Tabela 4. Coeficiente de correlação entre input e output. (PÉRICO et al., 2008).

\begin{tabular}{lcccc}
\hline & $\begin{array}{c}\text { Receita } \\
\text { financeira }\end{array}$ & $\begin{array}{c}\text { Resultado } \\
\text { financeiro }\end{array}$ & $\begin{array}{c}\text { Resultado } \\
\text { operacional }\end{array}$ & $\begin{array}{c}\text { Resultado } \\
\text { líquido }\end{array}$ \\
\hline Ativo total & 0.97 & 0,92 & 0,86 & 0,85 \\
$\begin{array}{l}\text { Operações } \\
\text { de crédito }\end{array}$ & 0,93 & 0,89 & 0,92 & 0,90 \\
$\begin{array}{l}\text { Depósitos } \\
\begin{array}{l}\text { Patrimônio } \\
\text { líquido }\end{array}\end{array}$ & 0,91 & 0,78 & 0,68 & 0,64 \\
\hline
\end{tabular}

Tabela 5. Resultados dos modelos DEA nas etapas iniciais. (PÉRICO et al., 2008).

\begin{tabular}{lccc}
\hline \multicolumn{1}{c}{ Variáveis } & $\begin{array}{c}\text { Modelo } \\
\text { inicial }\end{array}$ & $\mathbf{1}^{\text {a }}$ etapa & $\begin{array}{c}\text { Modelo } \\
\text { final }\end{array}$ \\
\hline Eficiência média & 24,41 & 79,37 & 84,14 \\
Desvio padrão & 7,37 & 16,84 & 15,26 \\
da eficiência & & & \\
Coeficiente de variação & 0,33 & 0,21 & 0,18 \\
Variância & 54,43 & 283,61 & 233,09 \\
Mínimo & 6,47 & 58,57 & 60,47 \\
Mediana & 23,58 & 77,07 & 80,43 \\
Máximo & 33,27 & 100 & 100 \\
Número de bancos & 0 & 4 & 5 \\
eficientes & & & \\
Bancos com & 12 & 0 & 0 \\
indicador < 50\% & & & \\
\hline
\end{tabular}


Tabela 6. Resumo de informações para inclusão de variáveis ( $1^{\text {a }}$ etapa). (PÉRICO et al., 2008).

\begin{tabular}{lccccc}
\hline Análise das variáveis & Correlação & Ef. Média & Variância & E = 100\% & E $<5 \%$ \\
\hline Ativo total & 0,44 & 79,37 & 283,61 & 4 & 3 \\
Operações de crédito & 0,37 & 71,55 & 533,34 & 5 & 1 \\
Depósitos & 0,40 & 83,3 & 286,48 & 5 & 0 \\
Receita financeira & 0,47 & 78,95 & 546,01 & 3 & 1 \\
Resultado operacional & 0,55 & 71,46 & 587,47 & 4 & 1 \\
Resultado financeiro & 0,53 & 75,98 & 478,21 & 5 & 1 \\
\hline
\end{tabular}

Outputs: resultado líquido e inputs: patrimônio líquido, ativo total e depósitos.

Os resultados do modelo final estão resumidos na Tabela 5, na última coluna. A eficiência média dos bancos atingiu $84,14 \%$ e cinco deles foram classificados como eficientes.

\subsection{Análise dos resultados}

A comparação dos resultados obtidos para as 12 instituições selecionadas do ranking "50 Maiores bancos", elaborado pelo Banco Central e pelo modelo DEA é apresentada na Tabela 7.

Cabe ressaltar algumas especificidades sobre os critérios de avaliação utilizados pelo Banco Central. O BC determina a grandeza de um banco a partir de duas informações financeiras. Inicialmente é considerado o ativo total do banco, ou seja, todos os bens e direitos que o mesmo possui. A outra informação relevante é a Intermediação financeira, que representa todos os recursos que o banco possui, provenientes de depósitos e que estão disponíveis para financiamento. A subtração da intermediação financeira do ativo total, por fim, determina a grandeza do banco. Portanto, o porte do banco é primordial na análise do Banco Central.

A análise DEA não considera o quão grande um banco é para classificá-lo como eficiente. O que é considerado, neste tipo de análise, é a utilização dos recursos (inputs) para o alcance do produto (output). A eficiência se refere à relação entre os resultados obtidos e os recursos empregados. Dessa forma, aspectos gerenciais (decisões de alocação de recursos) são mais relevantes do que o porte na análise DEA.

Como é possível perceber, por meio da Tabela 7, a classificação do Banco Central define o Banco do Brasil como o maior banco. No entanto, a análise DEA o classifica, em termos de eficiência, como o $3^{\circ}$ colocado, com indicador de eficiência de $78,86 \%$. Por meio desta análise ainda foi possível determinar que mesmo com uma redução de $38,86 \%$ no seu ativo total, acompanhada por uma redução de $62,22 \%$ nos seus depósitos, o Banco do Brasil teria potencial para incrementar seu resultado líquido em 26,81\%, conforme apresentado no Quadro 3.

No Quadro 3, a coluna target indica uma meta passível de ser realizada, a partir dos dados disponíveis, que
Tabela 7. Classificação do Banco Central e indicadores DEA. (PÉRICO et al., 2008).

\begin{tabular}{lclc}
\hline \multicolumn{1}{c}{ Banco } & $\begin{array}{c}\text { Classificação } \\
\text { (maiores) }\end{array}$ & Banco & $\begin{array}{c}\text { Escore } \\
\text { (eficiência) }\end{array}$ \\
\hline Banco do Brasil & $1^{\text {o }}$ & Citibank & 100 \\
Bradesco & $2^{\text {o }}$ & Safra & 100 \\
Caixa Econômica & $3^{\text {o }}$ & Nossa Caixa & 100 \\
Federal & $4^{\text {o }}$ & Bradesco & 100 \\
Itaú & $5^{\circ}$ & Itaú & 100 \\
Unibanco & $6^{\circ}$ & Caixa & 82 \\
Santander Banespa & $7^{\circ}$ & Banco do & 78,86 \\
ABN AMRO Real & & Brasil & \\
& $8^{\circ}$ & Santander & 75,93 \\
HSBC Bank Brasil & & Banespa & \\
& $9^{\circ}$ & HSBC Bank & 75,29 \\
Votorantim & & Brasil & \\
Safra & $10^{\circ}$ & Votorantim & 75,03 \\
Nossa Caixa & $11^{\circ}$ & Unibanco & 62,12 \\
Citibank & $12^{\circ}$ & ABN AMRO & 60,47 \\
& & Real & \\
\hline
\end{tabular}

Quadro 3. Potencial de melhoria do Banco do Brasil - análise DEA.

\begin{tabular}{lccc}
\hline \multicolumn{4}{c}{$\mathbf{7 8 , 8 6 \%}$ Banco do Brasil } \\
\hline & Atual & Target & $\begin{array}{c}\text { Potential } \\
\text { improvement } \\
(\%)\end{array}$ \\
\hline Ativo total & 252997,00 & 154678,69 & $-38,86$ \\
Depósitos & 137658,30 & 52008,87 & $-62,22$ \\
Patrimônio líquido & 16849,80 & 16849,80 & 00,00 \\
Resultado líquido & 4153,60 & 5267,03 & 26,81 \\
\hline
\end{tabular}

representa uma das combinações ótimas de recursos na obtenção de produtos.

O caso do Citibank representa o mais chamativo, pois na análise do BC ele é considerado o menor banco, ou seja, o último colocado, e na análise DEA ele é considerado um dos mais eficientes, ou seja, que melhor utiliza recursos na obtenção dos resultados. O Quadro 4 apresenta o potencial de melhoria e a margem de contribuição de suas variáveis.

Conforme apresentados no Quadro 4, os dados observados sobre as variáveis analisadas do Citibank representam a meta passível de ser alcançada, portanto, 
Quadro 4. Análise DEA (Citibank).

\begin{tabular}{lccc}
\hline \multicolumn{1}{c}{ 100,00\% Citibank } & & & $\begin{array}{c}\text { Peers: 0 } \\
\text { References: 0 }\end{array}$ \\
\hline \multicolumn{1}{c}{ Potential improvements } & & & Target \\
\hline Ativo total & Atual & 25137,00 & Potential improvement (\%) \\
Depósitos & 25137,00 & 6283,80 & 0,00 \\
Patrimônio líquido & 6283,80 & 3068,50 & 0,00 \\
Resultado líquido & 3068,50 & 198,60 & 0,00 \\
\hline \multicolumn{1}{c}{ Input/output contributions } & 198,60 & & 0,00 \\
\hline \multicolumn{1}{c}{ Variable } & & & Input/output \\
\hline Ativo total & Contribution & Input & Input \\
Depósitos & 34,854116 & Input & Output \\
Patrimônio líquido & 19,726797 & 45,419086 & \\
Resultado líquido & 100 & & \\
\hline
\end{tabular}

não há melhorias a serem realizadas. A margem de contribuição dos seus recursos (inputs) para obtenção do Resultado líquido (output) é a seguinte: o ativo total contribui em $34,85 \%$, os depósitos contribuem em 19,73\% e o patrimônio líquido do banco contribui em $45,42 \%$.

\section{Conclusões}

No presente artigo foi proposta a mensuração da eficiência de 12 bancos comerciais brasileiros, com utilização de análise por envoltória de dados. Essa técnica foi aplicada em um conjunto de bancos para o ano de 2005.

Foi apresentado, também, o ranking dos maiores bancos, elaborado pelo Banco Central. A classificação do BC é adequada ao que se propõe e utiliza dados financeiros pertinentes para avaliar a grandeza dos bancos.

A utilização da DEA permitiu a análise dos fatores que mais contribuíram para o alcance da eficiência, assim como o prévio conhecimento dos fatores que podem ser alterados para que empresas classificadas como ineficientes se tornem eficientes.

A análise DEA buscou a melhor combinação dos inputs, de forma a gerar maiores resultados, respeitando as diferentes escalas produtivas. Foram encontradas cinco combinações ótimas, que serviram de benchmarks para os bancos considerados menos eficientes. Uma combi- nação ótima significa que os recursos (inputs) foram otimizados, ou seja, foram mais bem utilizados para o resultado encontrado, que não necessariamente é o maior resultado.

Deve-se ressaltar que os resultados obtidos não se referem à eficiência de forma absoluta. Os bancos considerados eficientes somente são assim classificados dentre o grupo analisado. As combinações ótimas (de inputs para gerar outputs) representam as mais eficientes dentro do grupo analisado.

As divergências de análises, entre o índice de eficiência DEA e a classificação de maiores bancos, não tira o valor das mesmas, cada uma é legítima aos seus objetivos. É importante ressaltar, que embora os resultados de ambas as análises sejam distintos, podem ser utilizados conjuntamente, de forma a expandir a compreensão dos fatores que influenciam no desempenho dos bancos.

Por fim, respondendo à questão inicial deste trabalho, sobre se é possível ao maior banco ser também o mais eficiente, a resposta é sim. O maior banco pode ser o mais eficiente, desde que otimize a utilização de seus recursos, ou seja, aloque-os de forma mais eficiente. Conforme já mencionado, a eficiência de uma unidade produtiva, seja de bens ou serviços, é determinada pela relação entre os resultados obtidos e os recursos utilizados para produzi-los, e não com a riqueza da mesma. 


\section{Bank efficiency: are the largest banks the most efficient? A DEA analysis}

\section{Abstract}

Efficiency began to take on a greater relevance in Brazilian organizations when the country adopted an open market policy in the early 1990s. This paper analyzes the efficiency of commercial banks in Brazil based on data envelopment analysis (DEA), using the "Largest Banks" database of 2005, which is divulged periodically by Brazil's Central Bank. DEA is an operational research technique based on linear programming, whose objective is to analyze independent units comparatively. The technique was applied to the 12 largest commercial banks in order to ascertain if they are considered efficient in the use of their resources. Our findings indicated that bank size (a Central Bank criterion to classify banks) was not a determining factor in attributing efficiency to the banks, and that the use of inputs to achieve outputs was the most relevant criterion in the pursuit of a good performance and banking efficiency in this study.

Keywords: Data envelopment analysis. Efficiency. Commercial banks.

\section{Referências bibliográficas}

ASSAF NETO, A. Finanças Corporativas e Valor. São Paulo: Atlas, 2005.

BACEN - BANCO CENTRAL DO BRASIL. Sistema Financeiro Nacional. Estatísticas. 2006. Disponível em: <http://www.bcb. gov.br.>. Acesso em: 20 jul. 2006.

Sistema Financeiro Nacional. Manual de Normas e Instruções do Banco Central. 1996. Disponível em: <http:// www.bcb.gov.br.>. Acesso em: 12 jul. 2006.

BELLONI, J. A. Uma metodologia de avaliação da eficiência produtiva de Universidades Federais Brasileiras. Florianópolis, 2000. Tese - (Doutorado), Universidade Federal de Santa Catarina.

BRUNETTA, M. R. Avaliação da Eficiência Técnica e de Produtividade Usando Análise por Envoltória de Dados: Um estudo de caso aplicado a produtores de leite. Curitiba, 2004. Dissertação - (Mestrado), Universidade Federal do Paraná.

CAMARGO, A. S.; MATIAS, A. B.; MERLO, E. M. Desempenho dos bancos comerciais e múltiplos de grande porte no Brasil. São Paulo: Mimeo, 2004.

CASA NOVA, S. P. C. Utilização da análise por envoltória de dados (DEA) na análise das demonstrações contábeis. São Paulo, 2002. 317p. Tese - (Doutorado), Faculdade de Economia, Administração e Contabilidade, Universidade de São Paulo.

CASU, B.; MOLYNEUX, P. Efficiency in European banking. In: GODDARD, J.; MOLYNEUX, P.; WILSON, J. European Banking: Efficiency, Technology and Growth. Chichester: Jonh Wiley \& Sons Ltda, 2001.

CERETTA, P. S.; COSTA Jr, N. C. A. Avaliação e seleção de fundos de investimento: um enfoque sobre múltiplos atributos. Revista de Administração Contemporânea, Rio de Janeiro, v. 5, n.1, p. 7-27, Janeiro/Abril, 2001.

CHARNES, A. et al. Data envelopment analysis: theory, methodology, and application. Massachusetts: Kluwer, 1997.

CHICK, V. A evolução do sistema bancário e a teoria da poupança, do investimento e dos juros. Ensaios FEE, Porto Alegre, v. 15, n. 1, p. 9-23, 1986.

COOPER, W. W.; SEIFORD, L. M.; TONE, K. Data Envelopment Analysis - A comprehensive text with models, applications, references and DEA - Solver Software. United States of America: Kluwer Academic Publishers, 2003.

GITMAN, L. J. Princípios de Administração Financeira. São Paulo: Pearson, 2004.

GUDIN, E. Princípios de Economia Monetária. Rio de Janeiro: Agir, 1974.

HOWELLS, P.; BAIN, K. Economia Monetária: Moedas e Bancos. Rio de Janeiro: LTC, 2001.

HUGON, P. A moeda. São Paulo: Livraria Pioneira, 1972.

LINS, M. P. E.; MEZA, L. A. Análise por Envoltória de Dados e Perspectivas de Integração no Meio Ambiente de Apoio à Decisão. Rio de Janeiro: Coppe, 2000.

LOPES, J. C.; ROSSETTI, J. P. Economia Monetária. São Paulo: Atlas, 1998.

MACEDO, M. A. S.; SANTOS, R. M.; SILVA, F. F. Desempenho organizacional no setor bancário: uma aplicação da Análise por Envoltória por Dados. In: Encontro Nacional de Pós-Graduação em Administração - ENANPAD, 29, 2004. Anais... Curitiba PR, 2004.

MAYER, T. et al. Moeda, Bancos e a Economia. São Paulo: Campus, 1993.

MISHKIN, F. S. Moedas, Bancos e Mercados Financeiros. Rio de Janeiro: LTC, 2000.

NORMAN, M.; STOKER, B. Data Envelopment Analysis: the assessment of performance. Chichester: John Wiley, 1991.

SATHYE, M. Efficiency of Banks in a Developing Economy: the case of India. European Journal of Operational Research, Elseview, North Holland, n. 148, p. 662-671, 2002.

THANASSOULIS, E. A data envelopment analysis approach to clustering operating units for resource allocation purposes. International Journal of Management Science, Dearborn, MI 48126 USA, v. 24, n. 4, p. 463-476, 1996.

VEDULA, P; TRIPE, D. The efficiency of New Zealand's retail banks. In: New Zealand Finance Colloquium, Hamilton, New Zealand, 8, 2004. 


\section{Sobre os autores}

\section{Ana Elisa Périco}

\section{Daisy Aparecida do Nascimento Rebelatto}

\section{Naja Brandão Santana}

Departamento de Engenharia de Produção, Escola de Engenharia de São Carlos - EESC,

Universidade de São Paulo - USP, Avenida Trabalhador São-carlense, № 400, Centro, São Carlos, SP, Brasil,

e-mails: anaelisa@sc.usp.br; daisy@sc.usp.br; naja@sc.usp.br 